\title{
ANALYSIS OF THE ERRORS OF MEMS ACCELEROMETERS BY THE ALLAN VARIATION METHOD
}

In the article we obtained the generalized equation of errors of SINS accelerometers, its components give a characteristic of the influence of conversion coefficients errors, the inaccuracy in the installation of accelerometer measuring axes, the size effect and the displacement of accelerometer zeroes, and a block diagram of the formation of errors in the output signal of accelerometers is also made. The components of the random error of accelerometers, such as bias instability and acceleration random wolk, as well as due to the presence of white and exponentially correlated (Markov) noise, are analyzed. The models of forming the components of the random error of accelerometers from white noise and white sequence are given. The MEMS accelerometers of Gemini CAS211 / 291 type for each axis of the accelerometer with a sampling frequency of $100 \mathrm{~Hz}$ are investigated, as a result Allan variance graphs and the values of bias instability and velocity and acceleration random walk for each axis are determined. It was found that in the output signals of the accelerometers there is no Markov noise, and the $Z$ axis is noisier than the $X$ and $Y$ axes.

Keywords: accelerometer; the error equation; Allan variance; Allan deviation; bias instability; strapdown inertial navigation system.

Introduction. General statement of the problem. To solve the problem of estimation of mobile robot movement strapdown inertial navigation systems (SINS) are often use; they include accelerometers, gyroscopes and magnetometers.

The presence of accelerometers in the inertial system can determine the magnitude of linear acceleration affecting the mobile robot. However, firstly, the mobile robot is impractical to install mechanical accelerometers because of their large size. Therefore, miniature accelerometers in the form of microelectromechanical systems (MEMS) are being used. In this case, to determine the velocity and displacement (coordinates) it is necessary to carry out the integration (to determine movement, the double one is essential) or simple summation (for analog or discrete output). However, this assessment of motion parameters will be close, depending on the sampling frequency of accelerometer signal output and results in the accumulation of errors [6].

Secondly, accelerometers are characterized by zero drift, leading to changes in the components of the acceleration vector even in a static position. The magnitude of the drift depends on the type of accelerometer (miniature implement is less accurate).

Thirdly, integration and processing of inertial sensor data with sufficient accuracy required for frequency creates high computational load for which it may be necessary to allocate a separate microcontroller. In addition, the accelerometers are sensitive to high frequency of high-interference, to overcome the problem sophisticated filters of various types are used (Kalman filter, "alpha-beta" filter, etc.).

While analyzing the SINS accuracy characteristics caused by errors of accelerometers, the attention is paid to zero instability (offset) and residual systematic errors. This paper focuses on the instability of accelerometer zeros, which typically represent the sum of systematic $\delta a_{S}$ (Systematic Error) and random $\delta a_{R}$ (Random Error) components [4]:

$$
\delta a=\delta a_{S}+\delta a_{R} .
$$

Systematic error remains constant or changes while repeated measurements and accelerate transformation and random errors change randomly. The cause of the shift of input signal in accelerometer is execution of artifactual items on moving parts of a sensor and unbalance of electronic components of readout and processing system.

To investigate random errors of accelerometers the following methods of analysis are used:

- frequency analysis methods for the spectral power density (Power Spectral Density (PSD)) [1];

- temporal analysis techniques for Allan variations (Allan Variance (AVAR)) [8-10].

The spectral power density is defined as bilateral Fourier transform of the correlation function and describes the frequency distribution of random signal power

The spectral power density $S(\omega)$ is defined as the Fourier bilateral transform of the correlation function $K(\tau)$ and describes the frequency distribution of random signal power:

$$
S(\omega)=\frac{1}{2 \pi} \int_{-\infty}^{+\infty} K(\tau) e^{-i \omega \tau} d \tau .
$$

Allan variation is a method of analysis of time series to determine the characteristics of noise as a function of average time and it appears on a stationary platform according to the results of a record output 
accelerometer $\tilde{a}(t)$. Record of output accelerometer consists of $N$ samples of $T_{0}$ duration of the total length of the record $N T_{0}$. Alan variation method (variances) resembles a classical sample variance, but the difference lies in calculating not variances of centered random process variations but differences of neighboring deviations. This statistical evaluation allows to evaluate noise components of the output signal in the form of «white» noise or correlated Markov process. Alan variation method was originally developed to assess the error frequency standards, and later began actively used to estimate the parameters of inertial sensing elements (recommendations on the use of this method of analysis are given in the standards IEEE [8,9].

According to this method as a result of the test measurements initial array of $N$ measurements of acceleration $\tilde{a}(t)$ is received, to break this array on $K=N / M$ groups, where $M$ is the size of group of sequential measurements and the average value for each group is determined

$$
\bar{a}_{k}=\frac{1}{M} \sum_{i=1}^{M} a_{(k-1) M+i}, \quad k=1, \ldots, K .
$$

Calculating Allan variance is to determine the variance of value differences of means $\bar{a}_{k}$ of two neighboring groups with a time shift in correlations $\tau=M / f_{д}=M T_{0}$ where $f_{д}$ - the sampling frequency of accelerometer output signals:

$$
\sigma_{A}^{2}(\tau)=\frac{1}{2(K-1)} \sum_{k=1}^{K-1}\left[\bar{a}_{k+1}-\bar{a}_{k}\right]^{2} .
$$

However, in practice it is often determined not Allan variance $\sigma_{A}^{2}(\tau)$ but Allan deflection (Allan Deviation $(A D)) \sigma_{A}(\tau)$, followed by depending construction of Allan deviation from the average time and analysis inclination of different parts of the Allan deviation curve on which conclusions are drawn about the presence of various components of the error accelerometers (Fig. 1). In fact $\tau$ dimension is a group of averaging size $\mathrm{M}$ data. Allan Variance is connected with the spectral power density $S_{\omega}(f)$, which is a classic characteristic of a random process in the frequency domain:

$$
\sigma_{A}^{2}(\tau)=4 \int_{0}^{\infty} S_{\omega}(f) \cdot \frac{\sin ^{4}(\pi \tau f)}{(\pi \tau f)^{2}} d f .
$$

Analysis of Allan variations (variances) allows to divide different noise sources due to different time correlation and determine the value of each. To analyze Allan deviations $\sigma_{A}(\tau)$ depending on the correlation time $\tau$ and quantify individual components built in double logarithmic scale graph $\sigma_{A}=f(\tau)$ is commonly used (Fig. 1). Sectors, corresponding to right lines with different angle, allow to draw conclusions as to the existence of a noise parameter.

Allan variations allow to separate these noise components:

- quaizideterministic offset of zero signal or trend (slope +1 );

- random acceleration wander of accelerometer or gyroscope rate (slope +0.5$)$;

- offset instability or flicker noise (inclination 0);

- random wander (random drift) of accelerometer velocity or gyroscope angle (slope -0.5);

- quantization noise output (slope -1).

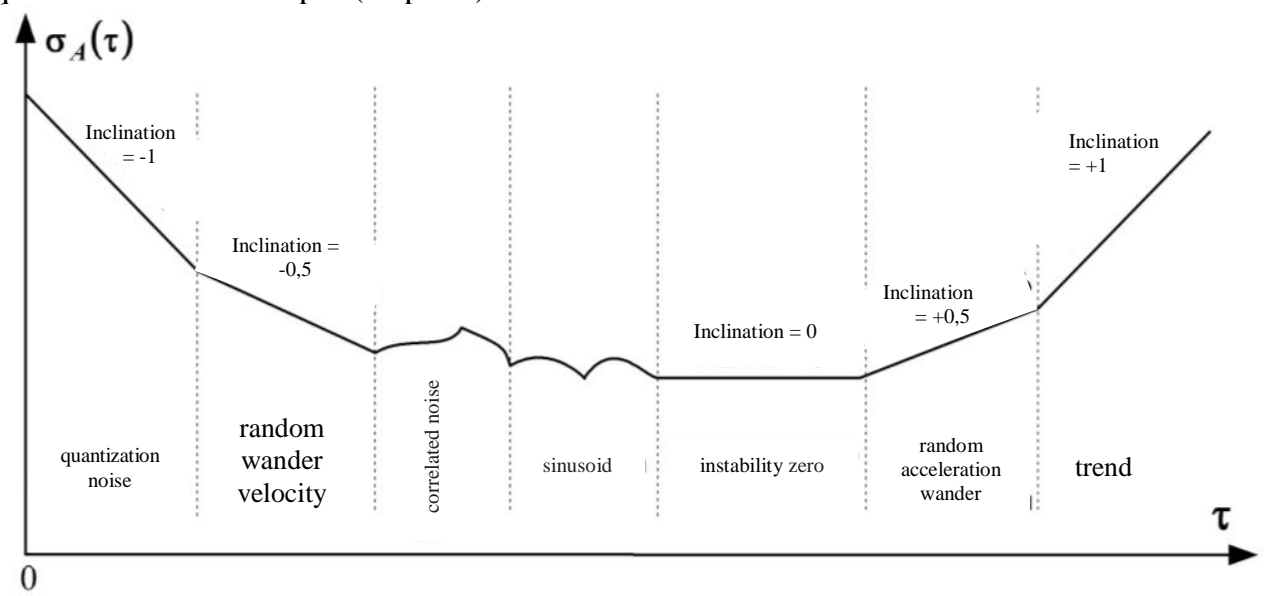

Fig. 1. Standard form of curve of Allan deviation 
Systematic error offset accelerometer zero $\delta a_{S}$ from equation (1) is the sum of the basic (Basic) $\delta a_{S B}$ and additional (Additional) $\delta a_{S A}$ of systematic errors:

$$
\delta a_{S}=\delta a_{S B}+\delta a_{S A}
$$

Typically, the main systematic error of the accelerometer will be different from the main bias of another accelerometer of the same type as for a group of similar accelerometers main systematic error is considered as a random error that is constant in this operating cycle (startup). It arises when the inclusion of an accelerometer and is described by a random variance with zero mean, variance $\sigma_{S}^{2}$ and differential equations $\delta \dot{a}_{S B}=0$. Constant offset is estimated in the process of calibration and excluded from the accelerometer readings in its functioning.

If there's sinusoidal error $A_{m} \sin \left(2 \pi f_{0} t\right)$ in accelerometer output signal, it is detected by Allan deviation and calculate its parameters of curve maximum coordinates $\sigma_{A \cdot \max }$ and $\tau_{\text {extr }}$ thus [9]:

$$
A_{m}=1.379 \cdot \sigma_{A \cdot \max } ; \quad f_{0}=\frac{0.371}{\tau_{\text {extr }}} .
$$

Additional errors of accelerometers are connected with their sensitivity to changes of external factors (Environment), the main ones are:

- sensitivity to angular velocity $\delta a_{S A . \omega} \omega$, where $\delta a_{S A . \omega}$ - the coefficient of accelerometer sensitivity to angular velocity relative to the respective axis $[\mathrm{m} /(\mathrm{rad} \cdot \mathrm{s})] ; \omega$ - angular velocity;

- sensitivity to changes in temperature $\delta a_{S A . t} \Delta t$, where $\delta a_{S A . t}$ - the coefficient of accelerometer sensitivity to temperature changes $[\mathrm{m} /(\mathrm{c} 2 \cdot \mathrm{C}], \Delta t-$ the temperature deviation from normal;

- sensitivity to vibration $\delta a_{S A . v} v$, where $\delta a_{S A . v}$ - accelerometer sensitivity coefficient to the frequency of vibration $[\mathrm{m} / \mathrm{s}] ; v-$ frequency vibration.

Problem statement. The article should:

1) obtain a generalized error equation of SINS accelerometers and on its basis to elaborate a flowchart of error formation in the accelerometer output signal;

2) analyze the components of accelerometers random error due to the influence of various destabilizing factors and bring model of random error component accelerometers of white noise and white sequence;

3) conduct a study of MEMS accelerometers determining the value of their constituents of random error for each axis of Allan deviation curves.

Presentation of basic material

Nominal output signals of three accelerometers $A_{X}, A_{Y}, A_{Z}$ can be represented as

$$
u^{A}=K^{A} \cdot E \cdot n
$$

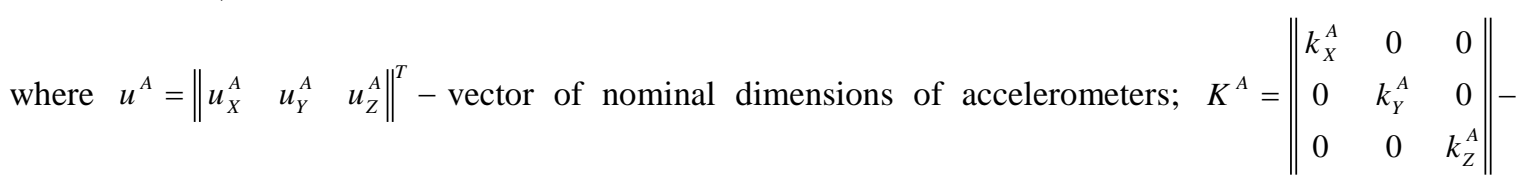
matrix of nominal coefficients of nominal accelerometer transformation; $k_{X}^{A}, k_{Y}^{A}$ та $k_{Z}^{A}-$ coefficients of accelerometer transformation $A_{X}, A_{Y}$ та $A_{Z} ; n=\left\|n_{X} \quad n_{Y} \quad n_{Z}\right\|^{T}$ - matrix of vector projection of imaginary acceleration of a triangle corner to its arcs; $E$ - unity matrix.

For real terms accelerometer output signals can be written as

$\tilde{u}^{A}=\tilde{K}^{A}\left(M^{A} n+a^{e}+\delta a\right)$,

where $\tilde{K}^{A}=K^{A}+\Delta K^{A}=K^{A}\left(1+\varepsilon_{K^{A}}\right) ; \Delta K^{A}$ and $\varepsilon_{K^{A}}$ - correspondently absolute and relative error of coefficient matrix of accelerator transformation; $\delta a=\left\|\delta a_{X}^{u} \quad \delta a_{Y}^{u} \quad \delta a_{Z}^{u}\right\|^{T}$ - vector of offset accelerometer zero having a dimension of output signal of accelerometer (when analog output - [O], the digital output - [Bit], the output frequency - $[\mathrm{Hz}]) ; a^{e}$-portable acceleration vector, its appearance is caused by a change in angular velocity related coordinate system $\dot{\omega}$ and centrifugal acceleration (in English terminology size effect - effect size) (Fig. 2); $M^{A}$ - directing cosines matrix that describes the deviation angles $\phi_{1}, \phi_{2}$ and $\phi_{3}$ and measuring axes accelerometer $O X^{i} Y^{i} Z^{i}$ of related mobile object of coordinate system $O X Y Z$ (Fig. 2) [4]:

$$
M^{A}=\left\|\begin{array}{ccc}
\cos \phi_{2} \cos \phi_{1} & \sin \phi_{2} & -\cos \phi_{2} \sin \phi_{1} \\
-\cos \phi_{3} \cos \phi_{1} \sin \phi_{2}+\sin \phi_{3} \sin \phi_{1} & \cos \phi_{3} \cos \phi_{2} & \cos \phi_{3} \sin \phi_{1} \sin \phi_{2}+\sin \phi_{3} \cos \phi_{1} \\
\sin \phi_{3} \cos \phi_{1} \sin \phi_{2}+\cos \phi_{3} \sin \phi_{1} & -\sin \phi_{3} \cos \phi_{2} & -\sin \phi_{3} \sin \phi_{1} \sin \phi_{2}+\cos \phi_{3} \cos \phi_{1}
\end{array}\right\| .
$$




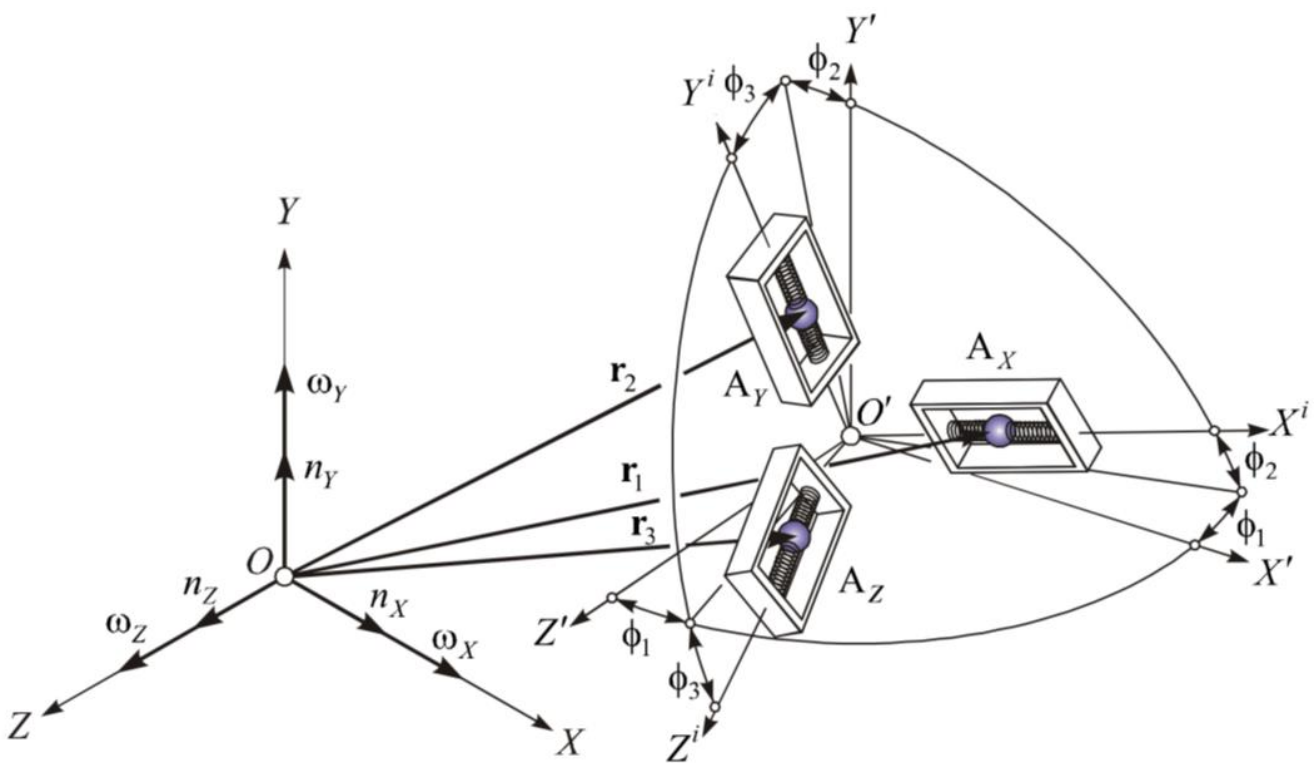

Fig. 2. The placement of accelerometers relativily to the arcs of connected frame

If to put that deflection angles $\phi_{1}, \phi_{2}$ and $\phi_{3}$, and have little value, a matrix $M^{A}$ can be written as follows:

$$
M^{A} \approx\left\|\begin{array}{ccc}
1 & \phi_{2} & -\phi_{1} \\
-\phi_{2} & 1 & \phi_{3} \\
\phi_{1} & -\phi_{3} & 1
\end{array}\right\|=\left\|\begin{array}{ccc}
1 & 0 & 0 \\
0 & 1 & 0 \\
0 & 0 & 1
\end{array}\right\|-\left\|\begin{array}{ccc}
0 & -\phi_{2} & \phi_{1} \\
\phi_{2} & 0 & -\phi_{3} \\
-\phi_{1} & \phi_{3} & 0
\end{array}\right\|=E-\left[M^{A} \times\right],
$$

where $E$ - unity matrix; $\left[M^{A} \times\right]$ - skew-symmetric matrix corresponding to the matrix $M^{A}$.

In matrix form of recording transfer acceleration can be recorded [4]:

$a^{e}=E_{1} M^{A}\left\{[\dot{\omega} \times] r_{1}+[\omega \times]\left([\omega \times] r_{1}\right)\right\}+E_{2} M^{A}\left\{[\dot{\omega} \times] r_{2}+[\omega \times]\left([\omega \times] r_{2}\right)\right\}+$

$$
E_{3} M^{A}\left\{[\dot{\omega} \times] r_{3}+[\omega \times]\left([\omega \times] r_{3}\right)\right\} \text {, }
$$

where $E_{1}=\left\|\begin{array}{lll}1 & 0 & 0 \\ 0 & 0 & 0 \\ 0 & 0 & 0\end{array}\right\|, E_{2}=\left\|\begin{array}{ccc}0 & 0 & 0 \\ 0 & 1 & 0 \\ 0 & 0 & 0\end{array}\right\|, E_{3}=\left\|\begin{array}{ccc}0 & 0 & 0 \\ 0 & 0 & 0 \\ 0 & 0 & 1\end{array}\right\|$, herewith $E_{1}+E_{2}+E_{3}=E ; \quad r_{1}, r_{2}$ and $r_{3}-$

vectors, connecting the start of coordinate system of connected frame linked with the mass center of respective accelerometers (Fig. 2).

In inertial measurements units (Inertial Measurement Unit $(I M U)$ ) [5] an error "size effect " will always take place, because values $r_{1}, r_{2}$ and $r_{3}$ are not equal to zero. If we assume that $r_{1}=r_{2}=r_{3}=r$, the ratio (7) takes the following form:

$$
a^{e}=M^{A}\{[\dot{\omega} \times] r+[\omega \times]([\omega \times] r)\},
$$

where correlation $[\dot{\omega} \times] r+[\omega \times]([\omega \times] r)$ - matrix form of well-known correlation of transfer acceleration and in vector form records as $\dot{\omega} \times r+\omega \times(\omega \times r)$.

To add to the equation (2) in dimension of acceleration $\operatorname{dim} a=\left[M / c^{2}\right]$ we multiply both sides by the matrix $\left(K^{A}\right)^{-1}$ and present the matrix as transform coefficients $\tilde{K}^{A}$ as the nominal amount of matrix $K^{A}$ and error matrix $\Delta K^{A}$, as a result we obtain:

$\left(K^{A}\right)^{-1} \tilde{u}^{A}=\left(K^{A}\right)^{-1}\left(K^{A}+\Delta K^{A}\right)\left(M^{A} n+a^{e}+\delta a\right)$.

Appointing $\tilde{a}=\left(K^{A}\right)^{-1} \tilde{u}^{A}$, we get

$\tilde{a}=\left(E+0.01 \delta K^{A}\right)\left(M^{A} n+a^{e}+\delta a\right)$,

where $\delta K^{A}=\left(K^{A}\right)^{-1} \Delta K^{A} \cdot 100 \%=\operatorname{diag}\left\|\delta k_{X}^{A} \quad \delta k_{Y}^{A} \quad \delta k_{Z}^{A}\right\|-$ diagonal matrix of relative errors of accelerometer transform coefficients [\%].

In expanded form recording of matrix of relative errors of accelerometer transform coefficients will take the following form: 


$$
\delta K^{A}=\left\|\begin{array}{|ccc||c||cc}
\frac{1}{k_{X}^{A}} & 0 & 0 \\
0 & \frac{1}{k_{Y}^{A}} & 0 \\
0 & 0 & \frac{1}{k_{Z}^{A}}
\end{array}\right\| \cdot\left\|\begin{array}{ccc}
\Delta k_{X}^{A} & 0 & 0 \\
0 & \Delta k_{Y}^{A} & 0 \\
0 & 0 & \Delta k_{Z}^{A}
\end{array}\right\| \cdot 100 \%=\left\|\begin{array}{ccc}
\frac{\Delta k_{X}^{A}}{k_{X}^{A}} & 0 & 0 \\
0 & \frac{\Delta k_{Y}^{A}}{k_{Y}^{A}} & 0 \\
0 & 0 & \frac{\Delta k_{Z}^{A}}{k_{Z}^{A}}
\end{array}\right\| \cdot 100 \% .
$$

Taking into account the possibility of presenting a matrix $M^{A}$ as a difference of unit and skew-symmetric matrix (3), the ratio (6) can be rewritten as follows:

$$
\tilde{a}=\left(E+0.01 \delta K^{A}\right)\left\{\left(E-\left[M^{A} \times\right]\right) n+a^{e}+\delta a\right\},
$$

Assume the error coefficient conversion $\delta k_{X}^{A}, \delta k_{Y}^{A}, \delta k_{Z}^{A}$ and deflection angles $\phi_{1}, \phi_{2}$ and $\phi_{3}$ and the values of the first order of smallness, then the obtaining of these parameters are the values of second order of smallness. Therefore, defying $0.01 \delta K^{A} \delta a$ and $0.01 \delta K^{A}\left[M^{A} \times\right]$ as the values of a higher order of smallness than the errors $0.01 \delta K^{A}, \delta a,\left[M^{A} \times\right]$ and considering the relation (6), equation (11) is written as follows:

$$
\tilde{a}=\left(E+0.01 \delta K^{A}\right) n-\left[M^{A} \times\right] n+\left(E+0.01 \delta K^{A}\right) a^{e}+\delta a \text {. }
$$

Flowchart of error formation in the accelerometer output signal is shown in Fig. 3. Scalar entry form value (12) takes the following form:

$$
\begin{aligned}
& \tilde{a}_{X}=\left(1+0.01 \delta k_{X}^{A}\right) n_{X}+k_{X}^{A}\left(\phi_{1} n_{Z}-\phi_{2} n_{Y}\right)+\left(1+0.01 \delta k_{X}^{A}\right) a_{X}^{e}+\delta a_{X} ; \\
& \tilde{a}_{Y}=\left(1+0.01 \delta k_{Y}^{A}\right) n_{Y}+k_{Y}^{A}\left(\phi_{2} n_{X}-\phi_{3} n_{Z}\right)+\left(1+0.01 \delta k_{Y}^{A}\right) a_{Y}^{e}+\delta a_{Y} ; \\
& \tilde{a}_{Z}=\left(1+0.01 \delta k_{Z}^{A}\right) n_{Z}+k_{Z}^{A}\left(\phi_{3} n_{Y}-\phi_{1} n_{X}\right)+\left(1+0.01 \delta k_{Z}^{A}\right) a_{Z}^{e}+\delta a_{Z} .
\end{aligned}
$$

If from the equation (12) subtract the actual imaginary vector acceleration we get generalized equation accelerometer errors:

$$
\Delta a=0.01 \delta K^{A} n-\left[M^{A} \times\right] n+\left(E+0.01 \delta K^{A}\right) a^{e}+\delta a .
$$

The first summand in the ratio (13) describes the effect of coeficint errors conversion, the second one shows malfunctioning installation of accelometer measuring axes, the third - the impact of portable acceleration on accelerometer error (size effect), the fourth - zero bias of accelerometers, which are determined by the ratio (1).

Components of random accelerometer error that are inertial sensor type defined by the presence of noise and noisy processes of various kinds:

$$
\delta a_{R}=\delta a_{W N}+\delta a_{B I}+\delta a_{A R W}+\delta a_{M N},
$$

where $\delta a_{W N}$ - component of random error characterized by the presence of white noise (White Noise, $(W N)$ ); $\delta a_{B I}$ - bias instabolity (Bias Instability, $(B I)$ ); $\delta a_{A R W}$ - random wander of acceleratio (Acceleration Random Walk, $A R W) ; \delta a_{M N}$ - component of random error characterized by the presence of exponential correlated (Markov) noise (Markov Noise, MN).

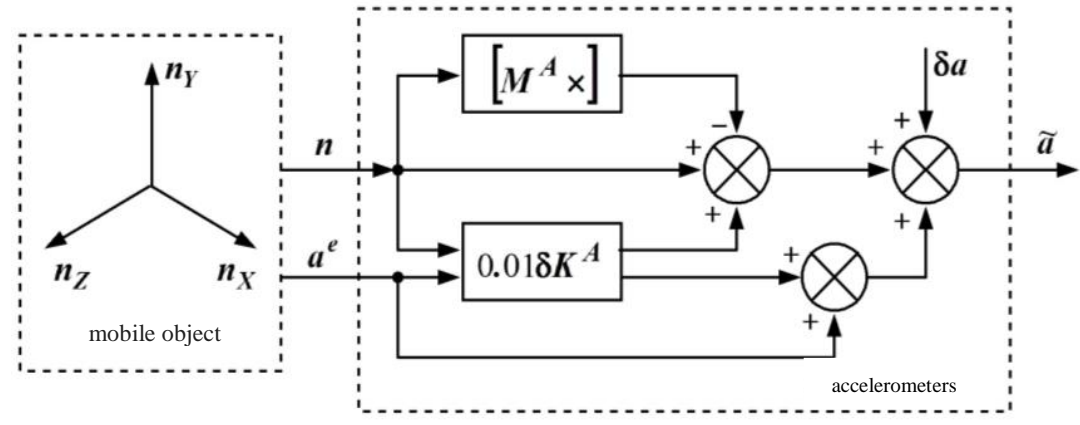

Fig. 3. Flowchart of error formation in output accelerometer signal

Various disturbances influence on the accelerometer output signal. Thus, thermomechanical noise is the most common in SINS MEMS accelerometers, which leads to fluctuations of acceleration that may be much larger than the actual sensor acceleration. To determine the speed of the mobile object accelerometer outputs are integrated, and in determining the coordinates they are the subject to a double integration over the time $t=N T_{0}$. If the accelerometer signal is taken at discrete time points of the sampling period $T_{0}$, the accelerometer noise can be described as white sequence (discrete white noise) $\delta a_{W N}(k), \quad k=1,2, \ldots$ with zero mean 
$M\left[\delta a_{W N}(k)\right]=M\left[\delta a_{W N}\right]=0$ and finite variance value $D\left[\delta a_{W N}(k)\right]=D\left[\delta a_{W N}\right]=\sigma_{W N}^{2}$. In this case, the error variance determining the linear velocity is defined as

$$
D\left[\int_{0}^{t} \delta a_{W N}(\tau) d \tau\right]=D\left[T_{0} \sum_{k=1}^{N} \delta a_{W N}(k)\right]=T_{0}^{2} N D\left[\delta a_{W N}\right]=T_{0} t \sigma_{W N}^{2},
$$

where value for the standard deviation (SCR) of error accumulation in determining the speed caused by the presence in the output signal of the accelerometer white noise is proportional to the square root of the time:

$$
\sigma_{V}(t)=\sigma_{W N} \sqrt{T_{0} t}=v_{V R W} \sqrt{t},
$$

where $v_{V R W}=\sigma_{W N} \sqrt{T_{0}}$-random walk of velocity (Velocity Random Walk, $(V R W)$ ) with dimension $\operatorname{dim} v_{V R W}=\left[M / c^{3 / 2}\right]$.

For accelerometer dimension $\operatorname{dim} v_{V R W}=[\mu \kappa g / \sqrt{\Gamma u}]$ is often used, where $1 \mu \kappa g / \sqrt{\Gamma u}=$ $=9.81 \cdot 10^{-6} M / c^{3 / 2}$. Accelerometers of aviation class have the noise level $(2 \div 10)_{M \kappa g} / \sqrt{\Gamma u}$, for IMU tactic class accelerometers of noise level $(10 \div 50)_{м \kappa g} / \sqrt{\Gamma u}$ is used and MEMS accelerometers of consumer class have the noise level $(50 \div 200){ }_{M \kappa g} / \sqrt{\Gamma u}$.

SCR moving determination is made by double integration of the white sequence [6]:

$$
\int_{0}^{t} \int_{0}^{\tau} \delta a_{W N}(v) d v d \tau=T_{0} \sum_{i=1}^{N} T_{0} \sum_{j=1}^{i} \delta a_{W N}(j)=T_{0}^{2} \sum_{i=1}^{N}(N-i+1) \delta a_{W N}(i) .
$$

Statistical properties of random error determination movements are as follows:

$$
\begin{gathered}
M\left[\int_{0}^{t} \int_{0}^{\tau} \delta a_{W N}(v) d v d \tau\right]=T_{0}^{2} \sum_{i=1}^{N}(N-i+1)^{2} M\left[\delta a_{W N}(i)\right]=0 ; \\
D\left[\int_{0}^{t} \int_{0}^{\tau} \delta a_{W N}(v) d v d \tau\right]=T_{0}^{2} \sum_{i=1}^{N}(N-i+1)^{2} D\left[\delta a_{W N}(i)\right]= \\
=\frac{T_{0}^{4} N(N+1)(2 N+1)}{6} D\left[\delta a_{W N}\right]=\frac{\sigma_{W N}^{2}\left(2 T_{0} t^{3}+3 T_{0}^{2} t^{2}+T_{0}^{3} t\right)}{6} \approx \frac{T_{0} t^{3} \sigma_{W N}^{2}}{3},
\end{gathered}
$$

i.e. on double integrating discrete of accelerometer white noise, random error of moving with zero mathematical double and non-zero dispersion appears and SCR error determination movement is

$$
\sigma_{S}(t)=t^{1.5} \sigma_{W N} \sqrt{\frac{T_{0}}{3}}=0.577 v_{V R W} t^{1.5}
$$

increasing proportionally $t^{1.5}$.

According to (17) simplifications while in SCR error determination movement there are absolute and relative errors:

$$
\begin{gathered}
\Delta \sigma_{S}(t)=0.707 \sigma_{W N} T_{0} \sqrt{t\left(t+\frac{T_{0}}{3}\right)}=0.707 v_{V R W} \sqrt{T_{0} t\left(t+\frac{T_{0}}{3}\right)} ; \\
\varepsilon_{\sigma_{S}}(t)=\frac{\Delta \sigma_{S}(t)}{\sigma_{S}(t)}=1.225 \sqrt{\frac{T_{0}}{t}}+0.707 \frac{T_{0}}{t}=\sqrt{\frac{T_{0}}{2 t}} \cdot\left(\sqrt{3}+\sqrt{\frac{T_{0}}{t}}\right) .
\end{gathered}
$$

Thus, the accelerometer type Gemini CAS211/291 manufactured by Silicon Sensing Systems Ltd. has its own noise (SCR) $100 \mathrm{M \kappa g} / \sqrt{\Gamma u}=9.81 \cdot 10^{-4} \mathrm{M} / \mathrm{c}^{3 / 2}$ [2], i.e. during 10 minutes random displacement error is accumulated (at $T_{0}=0.01 c$ ) $\sigma_{S}(600)=0.577 \cdot 9.81 \cdot 10^{-4} \cdot 600^{1.5}==8.32 \mathrm{M}$ with absolute and relative error of the ratio (19), respectively $4.2 \mathrm{~cm}$ and $0.5 \%$ (this is a decisive influence in the first term ratio (19)).

Fig. 4 shows the result of double integration of eight implementations of discrete white noise with sampling at $100 \mathrm{~Hz}$ at $v_{V R W}=100 \mathrm{M \kappa g} / \sqrt{\Gamma u}$. The dotted line shows the dependence of accumulated random error moving the current time calculated by the ratio (18). 


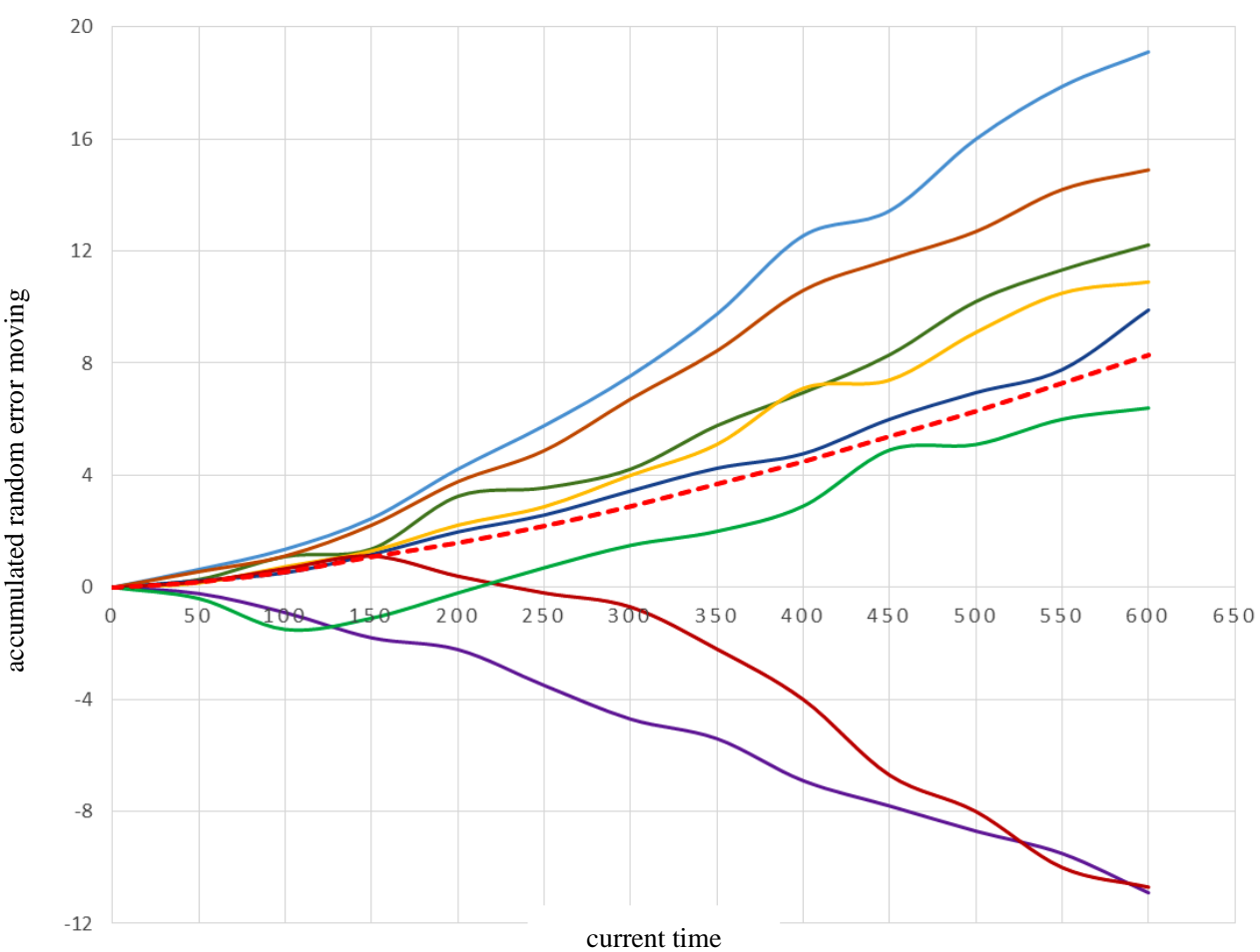

Fig. 4. Result of dual integration of eight implementations of white sequence

Bias instability (Bias Instability, $B I$ ) is caused by noise in electronic components removal and processing accelerometers. It is associated with so-called $1 / f$-noise or flicker noise (Flicker noise), which has a spectral density type $S(\omega)=\left\{\begin{array}{l}\frac{B^{2}}{2 \pi \omega}, \omega \leq \omega_{0} ; \\ 0, \omega>\omega_{0},\end{array}\right.$ where $\omega_{0}$ - boundary frequency, $B$ - coefficient of bias instability [3].

Flicker noise is a universal type of fluctuations and appears in almost all materials and components used in electronics. There is no general theory to describe flicker noise [7], which led to an approach based on fractional integration spectrum of white noise (in this case the order of half-integral white noise $w(t)$ ). Thus, if the white noise pass through a filter with transfer function $K(p)=\frac{1}{p^{1 / 2}}$, the fluctuations of the output filter will have a $1 / f$-spectrum (Fig. 5, a). In this case, the hypothetical filter serves as an integrator of fractional order.

Volatility factor of zero accelerometer is determined by the area of the Allan curve deflection at 0 (the minimum value of the Allan curve deflection): $B=\frac{\sigma\left(\tau=n T_{0}\right)}{0.664}$.

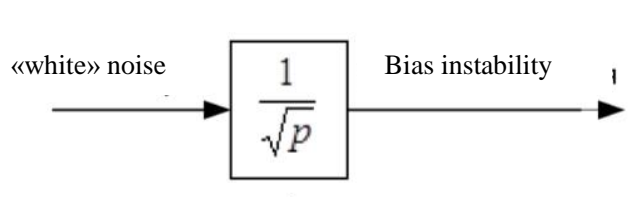

a)

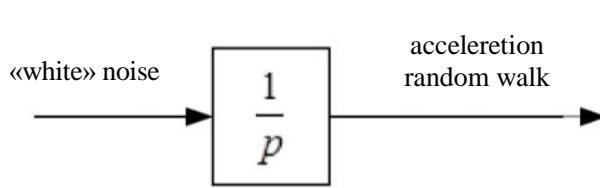

б)

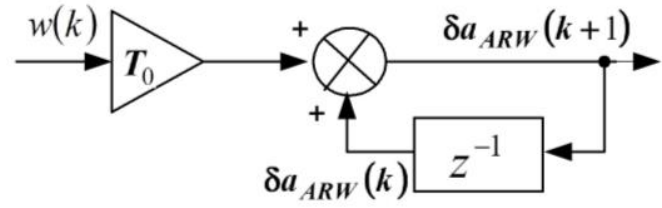

B)

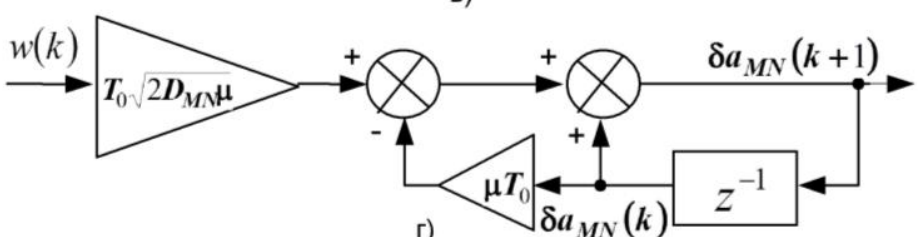

Fig. 5. Formation model of bias instability (a), acceleretion random walk (b), random walk of white noise $(c)$ and exponential correlared noise of white sequencie (c) 
Random accelerarion walk $\delta a_{A R W}$ is described as Wiener process (random walk) of a type $\frac{d}{d t} \delta a_{A R W}=w(t)$, where $w(t)$-generative white noise with zero mean $M[w(t)]=0$. Because $\delta a_{A R W}=\int_{0}^{t} w(\tau) d \tau$, then random acceleration walk is created as a result of letting the white noise through the integrator with transfer function $K(p)=\frac{1}{p}$ (fig. 5, b).

If a white noise $w(t)$ has spectral density $S_{0}$, so the spectral density of the random walk acceleration $S_{A R W}=\left|\frac{1}{i \omega}\right|^{2} \cdot S_{0}=\frac{S_{0}}{\omega^{2}}$. Then the derivative can be presented as $\frac{d}{d t} \delta a_{A R W} \approx$ $\approx \frac{\Delta\left(\delta a_{A R W}\right)}{\Delta t} \approx \frac{\delta a_{A R W}(k+1)-\delta a_{A R W}(k)}{T_{0}}=w(k)$, so for dicrete time $\delta a_{A R W}(k+1)=\delta a_{A R W}(k)+T_{0} w(k)$. Flowchart of formation of random acceleration walk for discrete time is shown in Fig. 5, b (symbol $z^{-1}$ sym $\neg$ vo $\neg$ lom designates the unit operator of delay range).

Random acceleration walk leads to the presence of lineal areas with a +0.5 slope on the Allan curve deviation (Fig. 1). To determine the spectral density of white noise that lets through the integrator for forming a random walk, it is necessary to find a square of Allan deviation with $\tau=3 \mathrm{c}$.

SCR of random acceleration walk is accumulated over time similarly (16):

$\sigma_{A R W}(t)=\sigma_{W N}^{*} \sqrt{T_{0} t}=a_{A R W} \sqrt{t}$,

where $\sigma_{W N}^{*}-$ SCR of generating white noise $w(t)$.

Exponential correlated (Markov) noise $\delta a_{M N}$ is described by correlative function

$K_{M N}(\tau)=D_{M N} e^{-\mu|\tau|}$,

where $D_{M N}$ - noise dispersion $\left[\mathrm{m}^{2} / \mathrm{s}^{4}\right] ; \mu-$ coefficient of damping of correlation function [ $\left.\mathrm{s}^{-1}\right]$. Instead of $\mu$ coeficient correlation time $T_{M N}=1 / \mu$ [s] is often used. Spectral density of exponential correlated noise is defined as

$S_{M N}(\omega)=\frac{D_{M N} \mu}{\pi\left(\mu^{2}+\omega^{2}\right)}$,

and the noise is described by differential equitation of a type

$\frac{d}{d t} \delta a_{M N}(t)+\mu \cdot \delta a_{M N}(t)=\sqrt{2 D_{M N} \mu} w(t)$.

If to let normalized white noise of unit intensity through the electric circuit of the transfer function $K(p)=\frac{\sqrt{2 D_{M N} \mu}}{p+\mu}$, the output will get exponential correlated noise:

$S_{\text {виX }}(\omega)=|K(p)|^{2} S_{B X}(\omega)=\left|\frac{\sqrt{2 D_{M N} \mu}}{i \omega+\mu}\right|^{2} \cdot \frac{1}{2 \pi}=\frac{D_{M N} \mu}{\pi\left(\omega^{2}+\mu^{2}\right)}$,

and it agrees with the correlation (22).

For discreet time the correlation (23) appears as

$\delta a_{M N}(k+1)=\delta a_{M N}(k)\left[1-\mu T_{0}\right]+T_{0} \sqrt{2 D_{M N} \mu} w(k)$.

In order to adequately switch from continuous model (23) to discrete (25), it is necessary to set the white sequence $w(t)$ with SCR $1 / \sqrt{T_{0}}$. Fig. 5, d presents the formation of exponential correlated noise from white sequence.

To determine the correlation time $T_{M N}$ (or parameter $\mu$ ) and dispersion $D_{M N}$ (or SCR $\sigma_{M N}$ ) of Markov noise, the method of Allan variations is used, whereby according to the Allan curve deflection (Fig. 1) the coordinates of local maximum $\tau_{M N}$ and $\sigma_{A . M N}$ between asymptote with slopes +0.5 and -0.5 , and the desired Markov noise parameters are defined as follows [1]:

$\sigma_{M N}=1.618 \cdot \sigma_{A . M N} ; \quad T_{M N}=0.529 \cdot \tau_{M N}$.

The accuracy of such Markov noise parameter defined by this method can be increased by increasing the length of the record noise. 
The paper studies MEMS accelerometers of Gemini CAS211 / 291 type which conducted for each accelerometer axis with a sampling rate of $100 \mathrm{~Hz}$. The results of the research in Fig. 6 show the Allan curves deviation.

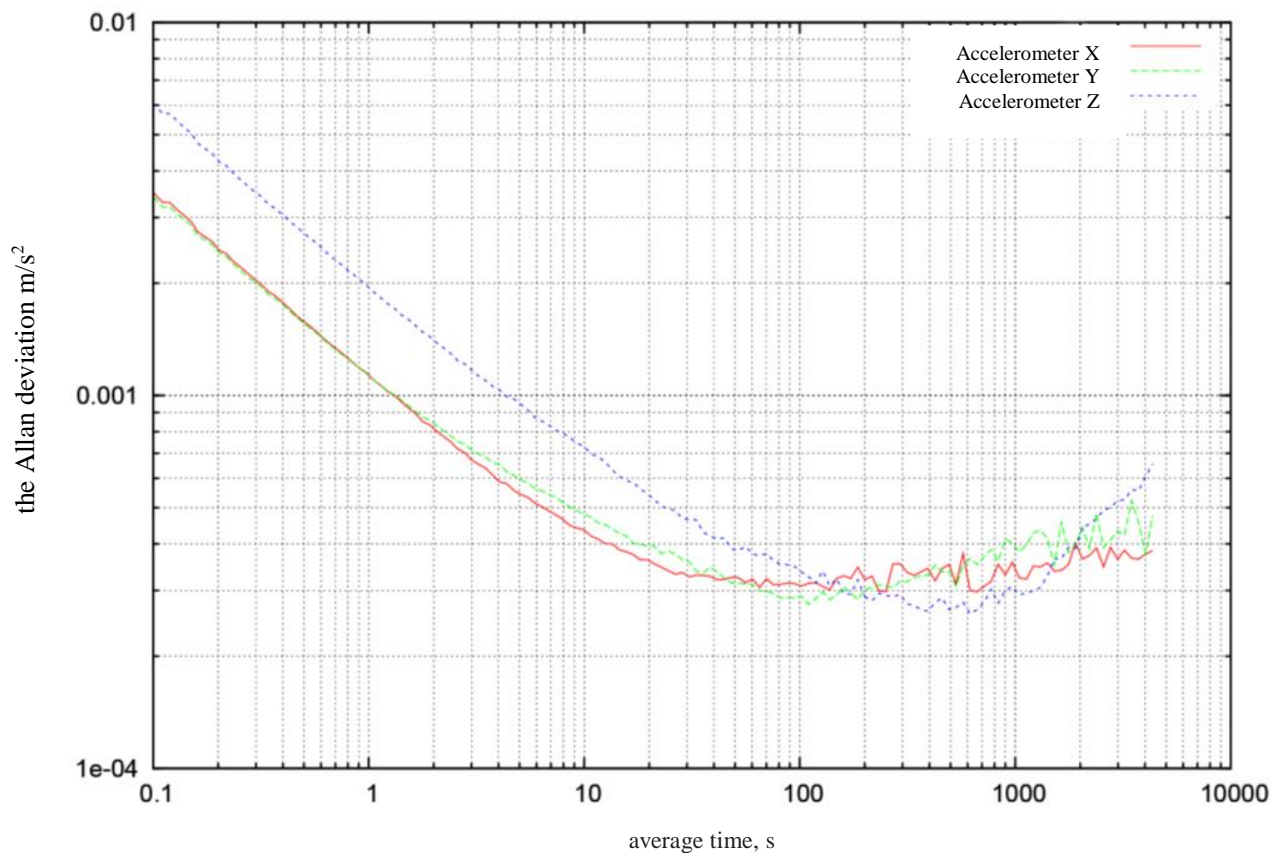

Puc. 6. The Allan deviation curves of MEMS accelemometer of Gemini CAS211/291type

For small values $\tau$, as expected, there is a slope of -0.5 of the Allan deviation curves corresponding to the presence of white noise in the accelerometer output signal. When $\tau=1 c$ random speed walk $v_{V R W}$ is determined. In the area $\tau=(40 \div 400) c$ the Allan deviation curves have minimum on the area of zero slope corresponding to bias instability. With further time increase of averaging $\tau$ the Allan deflection curves have a break and get a positive slope +0.5 characterizing the presence of random acceleration walk of accelerometer output signal. Local maximum between asymptote with slopes +0.5 and -0.5 on the Allan deviation curves is observed, suggesting the absence of Markov noise in the accelerometer output signal.

Analysis of results of measuring of accelerometer noise parameters is listed in Table 1 and shows that the $\mathrm{Z}$ axis of accelerometer has about twice the random walk rate than the $\mathrm{X}$-axis and $\mathrm{Y}$, and random accelerate walk is about $50 \%$ more. According to the preliminary conclusions it was connected with the gravitational effect (as in studies the $\mathrm{Z}$ axis is directed upwards) and measurement error of accelerometer scale factors. However, repeated similar studies have shown that the accelerometer scale factors have been calculated correctly, and their axes aligned horizontally (in this case the same results as in Fig. 6 are received). Therefore, it was concluded that the accelerometer samples the $\mathrm{Z}$ axis is noisier than the axes $\mathrm{X}$ and $\mathrm{Y}$.

Table 1

Results of measurement of accelerometer noise parameters

\begin{tabular}{|c|c|c|c|}
\hline & Bias instability & Random speed walk & $\begin{array}{c}\text { Random acceleration } \\
\text { walk }\end{array}$ \\
\hline $\begin{array}{l}\text { the } X \\
\text { axis }\end{array}$ & $\begin{array}{l}4.52 \cdot 10^{-4} \mathrm{~m} / \mathrm{s}^{2}= \\
1.63 \mathrm{~m} / \mathrm{h}^{2}(\operatorname{per} 670 \mathrm{~s})\end{array}=$ & $\begin{aligned} & 0.0011 \mathrm{~m} / \mathrm{s}^{1.5}= \\
= & 112 \mu \kappa g / \sqrt{\Gamma u}\end{aligned}$ & $\begin{array}{l}6.7 \cdot 10^{-4} \mathrm{~m} / \mathrm{s}^{1.5}= \\
=68 \mathrm{M \kappa g} / \sqrt{\Gamma u}\end{array}$ \\
\hline $\begin{array}{l}\text { the } Y \\
\text { axis }\end{array}$ & $\begin{array}{l}4.22 \cdot 10^{-4} \mathrm{~m} / \mathrm{s}^{2}= \\
1.52 \mathrm{~m} / \mathrm{h}^{2}(\text { per } 110 \mathrm{~s})\end{array}=$ & $\begin{aligned} & 0.0011 \mathrm{~m} / \mathrm{s}^{1.5}= \\
= & 112 \mu \kappa g / \sqrt{\Gamma u}\end{aligned}$ & $\begin{aligned} & 7.1 \cdot 10^{-4} \mathrm{~m} / \mathrm{s}^{1.5}= \\
= & 72 \mathrm{M \kappa g} / \sqrt{\Gamma u}\end{aligned}$ \\
\hline $\begin{array}{l}\text { the } \mathrm{Z} \\
\text { axis }\end{array}$ & $\begin{array}{c}3.92 \cdot 10^{-4} \mathrm{~m} / \mathrm{s}^{2}= \\
1.41 \mathrm{~m} / \mathrm{h}^{2}(\text { per } 620 \mathrm{~s})\end{array}=$ & $\begin{aligned} & 0.0020 \mathrm{~m} / \mathrm{s}^{1.5}= \\
= & 203.9 \mathrm{M \kappa g} / \sqrt{\Gamma u}\end{aligned}$ & $\begin{aligned} & 0.0011 \mathrm{~m} / \mathrm{s}^{1.5}= \\
= & 112 \mathrm{M \kappa g} / \sqrt{\Gamma u}\end{aligned}$ \\
\hline
\end{tabular}

\section{Conclusions:}

1. An error generalized equation of SINS accelerometers is obtained, elements of which characterize the impact of coefficient errors of conversion, installation malfunctioning of measuring axes of accelerometer, the impact on portable acceleration error ( size effect) and accelerometer zero offset and the flowchart of error formation in the accelerometer output signal is drawn. 
2. Components of accelerometer random error are analyzed, such as instability and random acceleration walk and due to the presence of white and exponential correlated (Markov) noise. A model of random error components of accelerometers from white noise and white sequence are mentioned.

3. Research of MEMS accelerometers of Gemini CAS211 / 291 type for each accelerometer axis with a sampling rate of $100 \mathrm{~Hz}$ is made. According to its results the Allan deflection curves were built. By the Allan deflection curves, zero volatility and random speed walks and acceleration for each axis areset and it is also found that the accelerometer output signal Markov noise is absent, and the $\mathrm{Z}$ axis is noisier than the axes $\mathrm{X}$ and $\mathrm{Y}$.

\section{Список використаної літератури:}

1. Измерительный модуль микросистемной бесплатформенной инерциальной навигационной системы / Р.В. Алалуев, Ю.В. Иванов, В.В. Матвеев, В.А. Орлов, В.Я. Распопов // Нано- и микросистемная техника. 2007. - № 9. - С. 61-64.

2. Бекмачев А. МЭМС-гироскопы и акселерометры Silicon Sensing: английские традиции, японские технологии / А.Бекмачев // Компоненты и технологии. - 2014. - №4. - С. 18-26.

3. Букингем М. Шумы в электронных приборах и системах / М.Букингем. - М.: Мир, 1986. - 399 с.

4. Матвеев В.В. Инерциальные навигационные системы / В.В. Матвеев. - Тула : Издательство ТулГУ, 2012. $199 \mathrm{c}$.

5. Рудик A.B. Багатофункціональні сенсори для мобільної робототехніки / A.B. Рудик // Вісник Інженерної академії України. - 2016. - № 1. - С. 30-36.

6. Рудик А.В. Методи оцінки просторового положення об'єктів / А.В. Рудик // Інтегровані інтелектуальні робототехнічні комплекси (ІІРТК-2016). Матеріали 9-ої міжнародної НПК. - К. : НАУ, 2016. - С. 31-33.

7. Groves P.D. Principles of GNSS, Inertial and Multisensor Integrated Navigation Systems. - Artech House, 2008. $505 \mathrm{p}$.

8. IEEE Std 1431-2004 Standard Specification Format Guide and Test Procedure for Coriolis Vibratory Gyros. -2004 .

9. IEEE Std 952-1997 Standard Specification Format Guide and Test Procedure for Single Axis Interferometric Fiber Optic Gyros. - 1997.

10. Oliver J. Woodman. An introduction to inertial navigation / J.Oliver. - Technical reports published by the University of Cambridge. - № 696. - 2007. - 37 p.

\section{References:}

1. Alaluev, R.V., Ivanov, Yu.V., Matveev, V.V., Orlov, V.A., Raspopov, V.Ya. (2007), «Izmeritel'nyy modul' mikrosistemnoy besplatformennoy inertsial'noy navigatsionnoy sistemy», Nano- i mikrosistemnaya tekhnika, vol. 9 , pp. 61-64.

2. Bekmachev, A. (2014), «MEMS-giroskopy i akselerometry Silicon Sensing: angliyskie traditsii, yaponskie tekhnologii», Komponenty i tekhnologii, vol. 4, pp. 18-26.

3. Bukingem, M. (1986), Shumy v elektronnykh priborakh i sistemakh, Mir, Moscow, 399 p.

4. Matveev, V.V. (2012), Inertsial'nye navigatsionnye sistemy, Izdatel'stvo TulGU, Tula, 199 p.

5. Rudyk, A.V. (2016), «Bagatofunkcional'ni sensory dlja mobil'noi' robototehniky», Visnyk Inzhenernoi' akademii' Ukrai'ny, vol. 1, pp. 30-36.

6. Rudyk, A.V. (2016), «Metody ocinky prostorovogo polozhennja ob'jektiv», Materialy 9-oi' mizhnarodnoi' NPK "Integrovani intelektual'ni robototehnichni kompleksy" (IIRTK-2016), Kyi'v: NAU, pp. 31-33, Ukraine.

7. Groves, P.D. (2008), Principles of GNSS, Inertial and Multisensor Integrated Navigation Systems, Artech House, $505 \mathrm{p}$.

8. IEEE Std 1431-2004 Standard Specification Format Guide and Test Procedure for Coriolis Vibratory Gyros, 2004.

9. IEEE Std 952-1997 Standard Specification Format Guide and Test Procedure for Single Axis Interferometric Fiber Optic Gyros, 1997.

10. Oliver J. Woodman (2007), An introduction to inertial navigation, Technical reports published by the University of Cambridge, vol. 696, 37 p.

RUDYK Andrii Viktorovych - Candidate of Technical Sciences, Associate Professor, PhD student of the Department of Computer and Elecical-Technical Systems and Technologies, National Aviation University, Kyiv.

Scientific interests:

- making the electrical and mechanical measurements електричних та механічних величин;

- navigation systems of mobile robotic technical complexes;

- processing of signals of micromechanical sensors of navigation systems.

E-mail: andrey05011971@ mail.ru.

Тел.: (050) 445-31-17.

Стаття надійшла до редакції 26.04.2017. 